\title{
Suppression Effectiveness of Extinguishing Agents Under Highly Dynamic Conditions
}

\author{
G. W. GMURCZYK, W. L. GROSSHANDLER and D. L. LOWE \\ Building and Fire Research Laboratory \\ National Institute of Standards and Technology \\ Gaithersburg, MD 20899 USA
}

\begin{abstract}
Alternatives to halon 1301 are sought which are effective fire suppressing agents and which do not create unacceptable safety, environmental, or systems compatibility problems. Investigations of eleven chemical compounds using a deflagration/detonation tube have revealed a great potential for the technique to study the fire suppression process. The facility is used to evaluate new suppressants, establishing their dynamic characteristics as well as elucidating complex suppression mechanisms occurring in fires under highly dynamic conditions typical of fast turbulent flames, explosions and detonations. A primary feature of the set-up is that the conditions of the ignition event do not affect the suppression process itself. Also, because an agent of interest is premixed with the fuel and air in a section of the tube divorced from the ignition event, the influences of ignition and entrainment of the agent into the flame are minimized. The tube is closed to allow the increase in pressure to influence the gas dynamics and chemistry. The deflagration/detonation tube arrangement has been successfully employed to clearly discriminate among the dynamic characteristics of the eleven alternative agents, revealing new unexpected effects. The results have been used to help select among the alternatives for full-scale testing in simulated aircraft dry bay fires.
\end{abstract}

KEYWORDS: fire suppression, halon 1301, extinguishing agents, detonation tube

\section{BACKGROUND}

The investigation described in this paper is part of a larger endeavor [1] directed at finding alternative compounds to halon 1301 for application to engine nacelle [2] and dry bay [3] in-flight aircraft fire protection. Dry bays refer to closed spaces in the wings and fuselage, inaccessible in flight, and into which fuel could spray and possibly ignite in combat. A fire might occur in the partially vaporized fuel/air mixture, with the clutter in the dry bay and confining panels restricting free expansion. If unattenuated the pressure will build and lead to flame acceleration, possibly ending in a destructive detonation. To be successful, 
suppression must occur within tens of milliseconds of the ignition event. Transitions to high-speed turbulent flames and detonations take place, in general, when the composition of a combustible mixture falls in an appropriate range and the geometric conditions promote the turbulent mixing process of the unburnt mixture and the products of reaction. When the process is confined in space, given enough distance, the flame will accelerate dramatically, reaching a supersonic regime of flow which is inherently associated with the presence of shock waves. Depending on the details of the geometry the flame may approach its theoretical Chapman-Jouguet velocity, accompanied by high pressures. Even a slight variation in composition of the combustible mixture near the detonation transition limit may cause a change in flame velocity of an order of magnitude. As a result the pressure waves can generate destructive pressures (making suppression essential) and propagate within a compartment at exceptional speeds (making positive intervention difficult). While there exists an extensive literature on detonation phenomena (e.g., [4-6]), interaction between a suppressant and a combustion/shock wave is not well understood.

The conditions achieved in the facility described in this paper have been chosen to shed light on the behavior of various agents during the most destructive conditions of a dry bay fire. Chapman and Wheeler [7] first noted that a methane/air flame could be accelerated to a terminal velocity in a shorter distance within a circular tube by placing obstacles into the flow. Lee $e t$ al. [8] employed that observation for studying quasi-detonations in various combustible mixtures. A quasi-detonation propagates at a lower velocity (even by $40 \%$ ) relative to true detonation. Its structure however is much more complex and the mechanism of propagation is not fully understood.

The design of the present detonation/deflagration tube is based directly upon the work of Peraldi et al. [9]. The objectives of the study are to make use of the facility for analyzing the suppression phenomena, and to screen alternative agents under highly dynamic conditions. The eleven alternative agents studied are listed in Table 1 . The boiling points at $101 \mathrm{kPa}$, vapor pressures at $295 \mathrm{~K}$, molecular weights and constant pressure specific heats at room temperature are also tabulated for each.

TABLE 1. Thermodynamic data for alternative agents

\begin{tabular}{|c|c|c|c|c|c|}
\hline Compound/Formula & $\begin{array}{l}\text { Boiling } \\
\text { Pt. }{ }^{2}, \mathrm{~K} \\
\end{array}$ & $\begin{array}{l}\text { Molec. Wt. } \\
\mathrm{kg} / \mathrm{kmole}\end{array}$ & $\begin{array}{l}\text { Sat. Liquid } \\
\text { Dens, }{ }^{\mathrm{b}}, \mathrm{kg} / \mathrm{m}^{3}\end{array}$ & $\begin{array}{l}\mathrm{P}_{\text {vap }}{ }^{\mathrm{b}} \\
\mathrm{MPa}\end{array}$ & $\begin{array}{c}C_{p}{ }^{b} \\
k J / k g / K\end{array}$ \\
\hline$\overline{F C-116}\left(C_{2} F_{6}\right)$ & $\overline{195}$ & 138 & $258^{c}$ & 3.07 & 768 \\
\hline Haton $1301\left(\mathrm{CF}_{3} \mathrm{Br}\right)$ & 215 & 149 & 1437 & 1.59 & 483 \\
\hline $\mathrm{HFC}-32 / \mathrm{HFC}-125$ & 220 & 67 & 1064 & 1.50 & 944 \\
\hline$\left(\mathrm{CH}_{2} \mathrm{~F}_{2} / \mathrm{C}_{2} \mathrm{HF}_{5}\right)$ & & & & & \\
\hline $\mathrm{HFC}-125\left(\mathrm{C}_{2} \mathrm{HF}_{5}\right)$ & 225 & 120 & 1212 & 1.27 & 787 \\
\hline $\mathrm{HCFC}-22\left(\mathrm{CHF}_{2} \mathrm{Cl}\right)$ & 232 & 87 & 1211 & 1.02 & 659 \\
\hline $\mathrm{FC}-218\left(\mathrm{C}_{3} \mathrm{~F}_{8}\right)$ & 236 & 188 & 1352 & 0.88 & 837 \\
\hline $\mathrm{HFC}-134 \mathrm{a}\left(\mathrm{C}_{2} \mathrm{H}_{2} \mathrm{~F}_{4}\right)$ & 247 & 102 & 1217 & 0.70 & 853 \\
\hline $\mathrm{HFC}-227\left(\mathrm{C}_{3} \mathrm{HF}_{7}\right)$ & 258 & 170 & 1412 & 0.46 & 800 \\
\hline $\mathrm{HCFC}-124\left(\mathrm{C}_{2} \mathrm{HF}_{4} \mathrm{Cl}\right)$ & 261 & 137 & 1372 & 0.42 & 824 \\
\hline FC-318 (cyclo-C $\left.{ }_{4} F_{8}\right)$ & 267 & 200 & 1540 & 0.31 & 780 \\
\hline $\mathrm{HFC}-236 \mathrm{fa}\left(\mathrm{C}_{3} \mathrm{H}_{2} \mathrm{~F}_{6}\right)$ & 271 & 152 & 1380 & 0.25 & 800 \\
\hline FC-3110 $\left(\mathrm{C}_{4} \mathrm{~F}_{10}\right)$ & 271 & 238 & 1520 & 0.26 & 794 \\
\hline
\end{tabular}

\footnotetext{
a Standard pressure
}

btandard temperature

${ }^{c}$ Gas density @ $4.2 \mathrm{MPa}$, standard temperature. 


\section{APPARATUS}

Suppression effectiveness under highly dynamic conditions includes the capability of an agent to decelerate the propagating flame and simultaneously attenuate the hazardous shock which precedes it. A deflagration/detonation tube has been designed and built to produce a repeatable combustion wave in which the shock Mach number and the presence of a flame can be precisely measured. A feature of the set-up is that the conditions of the ignition event do not affect the suppression process itself. Others have shown (e.g., [10]) that when injecting the agent into a test chamber after igniting the fuel, there is a difficulty in repeating the suppression event because what occurs before agent addition can dominate the overall dynamics of the process. In the other extreme, the fuel, air and agent can be premixed in a closed reaction vessel, but such a test is more relevant to inerting studies than active suppression. The strength of the ignition source also has a significant impact on whether a flame will or will not propagate in an inertion experiment [11].

In the present deflagration/detonation tube there are two sections: the test section contains the agent under consideration well stirred with the combustible mixture; the driver section contains the same air/fuel mixture, but no agent. Thus the effect of physically mixing the agent into the combustible gases is removed (as in an inertion experiment), the dynamics of the interaction between a non-inhibited combustion wave and the agent is preserved (as in the actual aircraft dry bay), and the influence of the ignition source is minimized by generating a fully established flame before encountering the inhibiting compound. Other characteristics of the facility are the order-of-magnitude shorter residence time of the agent in the reaction zone when compared to the traditional cup burner apparatus for measuring suppression concentration [12], the pressure effects on the gas dynamics as well as on the chemistry of the oxidation and inhibition processes, and the range of initial stoichiometries (lean to rich) and initial pressures $(10 \mathrm{kPa}$ to $150 \mathrm{kPa}$ ) that can be accommodated.

A schematic of the set-up is shown in Figure 1. Stainless steel tubing, $7.5 \mathrm{~m}$ long and 50 $\mathrm{mm}$ inside diameter, constitutes the body of the apparatus. The driver section is $5 \mathrm{~m}$ long, and is equipped at the closed end with a spark plug for igniting the combustible mixture. The ignition energy is delivered in a microexplosion of a tin droplet short-circuiting the tips of nichrome electrodes connected to an 80 volt $\mathrm{AC}$ power supply. The driver section is filled with the gaseous fuel and the oxidizer only. The test section is $2.5 \mathrm{~m}$ long, and is filled with fuel, oxidizer and the desired amount of gaseous flame inhibitor. The test section is separated from the driver section by a $50 \mathrm{~mm}$ diameter, stainless steel, high vacuum gate valve. Spiral-shaped obstructions made of $6.4 \mathrm{~mm}$ stainless steel rods with a pitch equal to the inner diameter of the tube are inserted into both sections of the tube. They are designed to produce an area blockage ratio of $44 \%$, the value shown by Lee [8] to promote a quasi-detonation in their facility. The oxidizer used in all the experiments was breathing grade air, at a total pressure up to $100 \mathrm{kPa}$. Ethene (CP grade, $99.5 \%$ vol. purity) was chosen as the fuel because previous studies [9] indicated that by adjusting the blockage ratio, tube length and the stoichiometry, a combustion wave could be generated in a subsonic, quasi-detonation, or full detonation mode. The speed and magnitude of the pressure wave are measured with piezo-electric pressure transducers located at the end of the test section, and the motion of the flame is monitored with fast photodiodes sensitive to the visible regime of radiation. Data are collected via electronic circuitry with a multichannel, digital storage oscilloscope. 


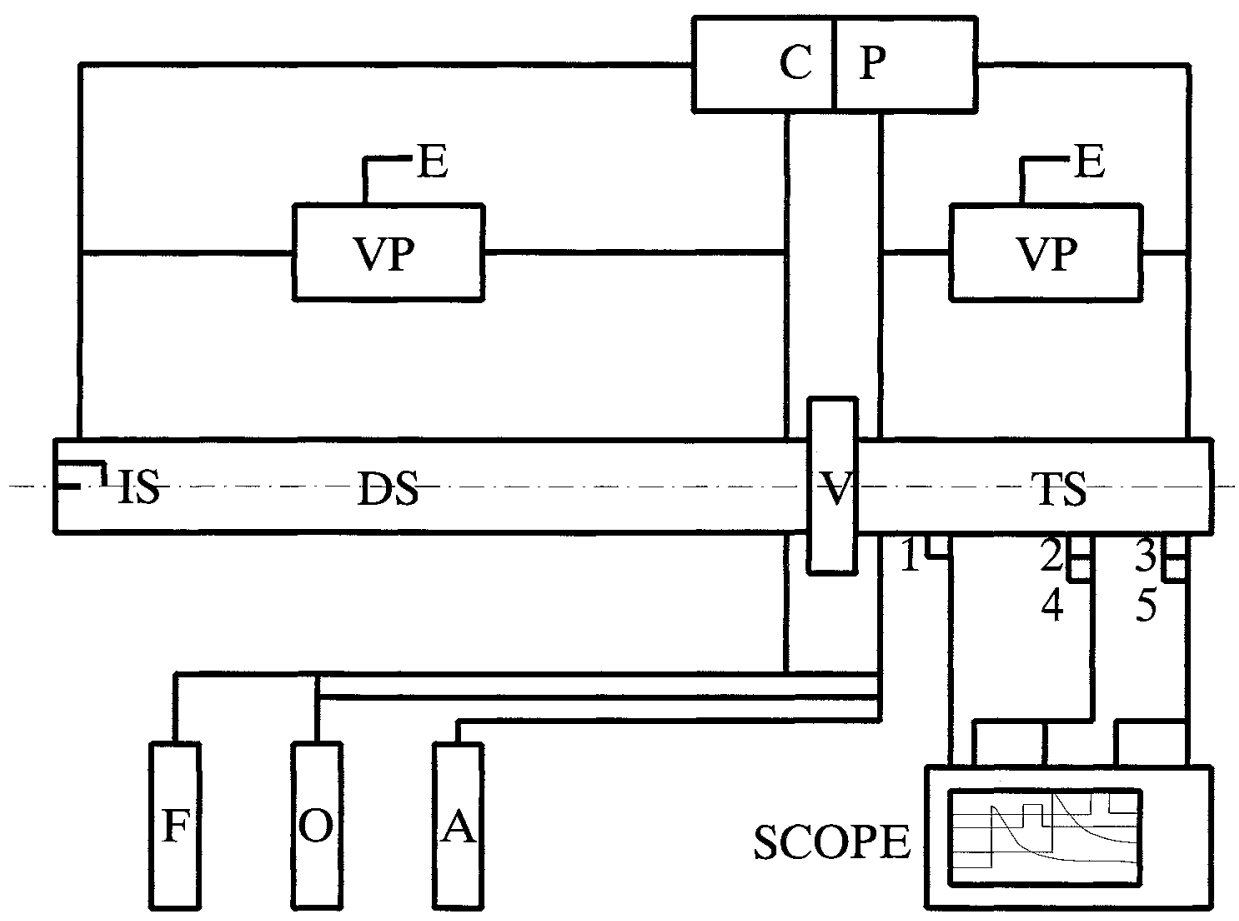

FIGURE 1. Schematic of the deflagration/detonation tube facility installed at NIST for the suppression studies in fast turbulent flames, explosions and detonations. DS - driver section, TS test section, V - gate valve, CP - dual circulating pump, VP - vacuum pump, E - exhaust, IS ignition source, $\mathrm{F}$ - fuel, $\mathrm{O}$ - oxidizer, A - agent, 1 - triggering transducer, 2,3 - piezo-electric dynamic pressure transducers, 4,5 - visible radiation fast photodiodes, SCOPE - collects two signals from pressure transducers plus two signals from photodiodes.

\section{EXPERIMENTAL PROCEDURE}

The composition of the mixture in each section was adjusted using the method of partial static pressures in such a way as to maintain equal total pressures on both sides of the gate valve. Likewise, the fuel/air ratio of the combustible mixture itself was kept constant in both sections, while the concentration of agent was varied between runs. Before each experiment the whole system was evacuated down to about $10^{-1} \mathrm{~Pa}$. The two sections were filled separately with the appropriate mixtures, and after filling the gases were homogenized independently using a double, spark-free circulating pump, recirculating the entire tube volume a total of twenty times. The mixtures were left for five minutes to become quiescent. About ten seconds prior to ignition, the gate valve was opened manually. After ignition, the flame propagated into the driver section and accelerated quickly due to the intense turbulence created by the interactions of the flow with the obstacles, generating a shock wave ahead of it. After passing through the open gate valve the flame/shock system 
encountered the same combustible mixture and a certain amount of agent in the test section. Depending on the concentration of the agent, the flame was successively decelerated and the pressure wave was attenuated. The following factors were investigated [3] with no suppressant in the test section to determine if they would influence the operation of the facility or the interpretation of the results: the presence of the gate valve, the speed of opening of the gate valve, the mixing time of the components before ignition, the ignition voltage and cleaning the tube between runs. The primary independent variables of fuel/air ratio, initial pressure in the system, and the presence of the obstacles were also studied.

The experiments conducted in the present study were for a lean ethene/air mixture at an equivalence ratio of 0.75 . The concentration of the eleven agents was increased from 0 to a value which reduced the pressure and shock Mach number to the condition found when no fuel were present at all in the test section. The initial temperature was ambient $(295 \pm 3$ $\mathrm{K}$ ) and the total pressure was maintained equal to $100 \pm 0.1 \mathrm{kPa}$.

The experimental procedure which was developed allows one to obtain flame/shock speeds reproducible from run to run within $\pm 2 \%$. Pressure ratios downstream of the shock wave exhibited a higher variability, $\pm 20 \%$, because of the complex interactions between the spiral rod insert and the shock wave.

\section{RESULTS AND ANALYSIS}

The Mach number and pressure ratio are used to compare the suppression effectiveness of the different agents. The flame deceleration and pressure attenuation were measured with two pressure transducers and two photodiodes located $2.2 \mathrm{~m}$ beyond the gate valve and 0.3 $\mathrm{m}$ from the far end of the tube. The Mach number is based upon the speed of sound in the unburnt test mixture, and the pressure ratio is calculated using the magnitude of the first pressure pulse.

In a previous series of experiments [3] the initial total pressure in the system was varied from 20 to $100 \mathrm{kPa}$, and the behavior of chemically inert nitrogen and chemically active $\mathrm{CF}_{3} \mathrm{Br}$ were compared. To summarize those results, one can state that the initial pressure was found to be an important parameter in the flame suppression process and that halon 1301 appeared to be about ten times more effective on the volume basis in decelerating a fast flame and attenuating a shock wave than nitrogen.

Oscilloscope signals obtained for test mixtures containing either $1 \%$ or $10 \%$ (vol.) $\mathrm{C}_{4} \mathrm{~F}_{10}$ are shown in Figures 2 and 3. Figure 2 depicts four signals recorded by the scope via electronic amplifiers. The two lower signals represent the transient pressures across the shock wave structure as it travels through the test section. One can see the time interval and frequency of the passage between the two pressure transducers. The structure of the shock wave is complex, resulting from obstacle reflections and from possible consecutive local explosions taking place in the mixing region between the obstacles. The amplitude and speed of the wave is proportional to its strength. The two upper signals refer to the visible radiation taken by the photodiodes located at the same distances as the pressure transducers. Such an arrangement provides information on the speed of the flame and the distance between the shock and flame. It was found that the amplitude and speed of the 


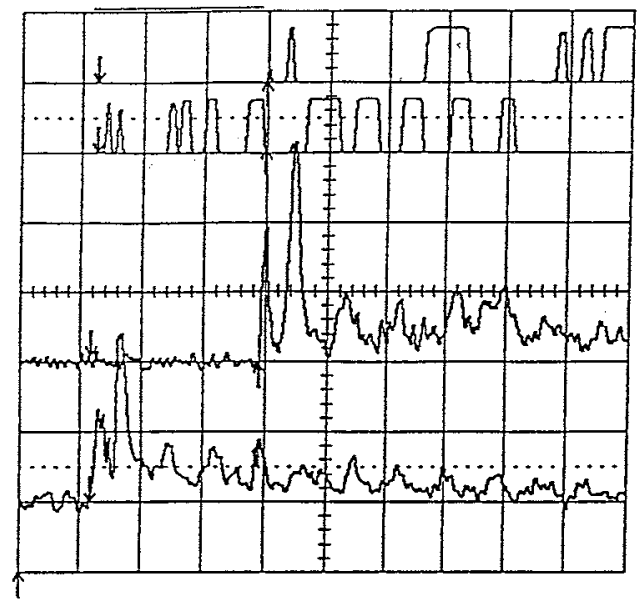

FIGURE 2. Suppression of $5 \%$ vol. ethene/air mixture with $1 \%$ vol. $\mathrm{C}_{4} \mathrm{~F}_{10}$. Initial conditions: temperature, $295 \mathrm{~K}$; pressure, $100 \mathrm{kPa}$. The two lower signals come from the pressure transducers; the two upper ones represent the radiation recorded by the photodiodes.

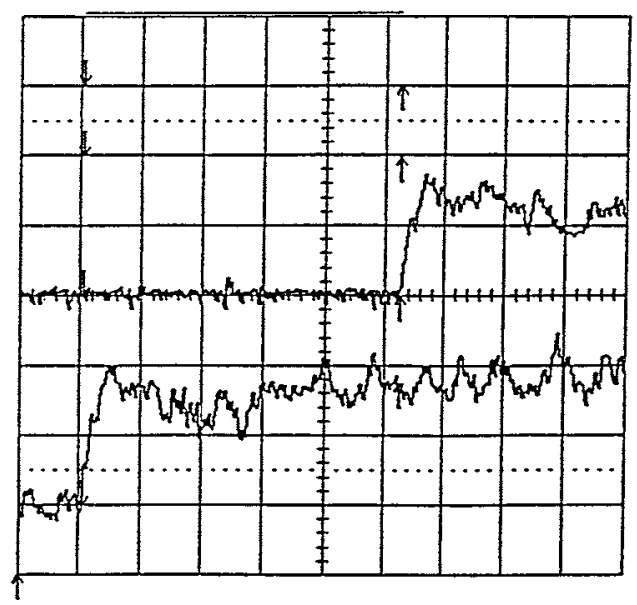

FIGURE 3. Suppression of $5 \%$ vol. ethene/air mixture with $10 \%$ vol. $\mathrm{C}_{4} \mathrm{~F}_{10}$. Initial conditions: temperature, $295 \mathrm{~K}$, pressure, $100 \mathrm{kPa}$. The two lower signals come from the pressure transducers significantly attenuated - the scale is magnified $8 \mathrm{x}$ relative to Figure 2; the photodiodes did not record any radiation. 
pressure wave, and the speed of the trailing flame, were dependent on the concentration of an agent in the mixture. It was determined that the flame always followed the shock wave in such a way that both speeds were equal. However when the amount of the agent in the mixture increases, the distance between the shock and flame increases as well, up to around $0.1 \mathrm{~m}$. At the extinguishing concentration the radiation disappears, which indicates the absence of the flame. Figure 3 shows the situation at extinction, in which the pressure wave amplitude is attenuated by a factor of eight and the wave speed by a factor of three. Radiation is no longer present. The structure of the pressure wave following extinction can be compared to the wave that is only slightly suppressed, to see that the consecutive pressure jumps disappear, possibly indicating that the localized explosions in the mixing region between the obstacles are no longer present.

The results for all the agents are presented in Figures 4 through 7 . The amount of agent is expressed in two ways, as a mass fraction and as a partial pressure fraction. The Mach numbers and pressure ratios at zero represent the pure combustible mixture with no flame suppressing agent present. As one can see, the dynamics of the suppression process and the energy carried depend strongly on the agent concentration and agent type. The Mach number of the pure combustible mixture is around 3.4 and the pressure ratio is around 18 . At the other extreme (100\% suppressant in the test section) the Mach number is around 1.3 and the pressure ratio is about 3 . Those values are typical for all the agents under investigation.

Figure 5 shows the dependence of the shock wave Mach number versus agent mass fraction. One can see that the extinguishing concentrations for all the compounds are between $40 \%$ and $50 \%$ (mass). However at low concentrations the Mach numbers are even higher for some agents than the value for the pure combustible mixture. The highest Mach number occurs for the $\mathrm{CH}_{2} \mathrm{~F}_{2} / \mathrm{C}_{2} \mathrm{HF}_{5}$ mixture. At high concentrations all the agents curves tend to converge. The highest extinguishing concentration is for HCFC-22 $\left(\mathrm{CHF}_{2} \mathrm{Cl}\right)$. The respective shock pressure ratios are shown in Figure 7 . One can see that some agents (primarily those containing hydrogen atoms) produce a large pressure rise, even higher than that for the pure combustible mixture. The maximum pressure ratio is $45: 1$ for the HFC$32 / 125$ mixture. At low concentrations $\mathrm{C}_{2} \mathrm{~F}_{6}$ seems to be the best of all the agents, but similarly to Figure 5, at high concentrations all the curves converge above $40 \%$ (mass).

Figures 4 and 6 show the dependence of the Mach number and pressure ratio versus partial pressure fraction. On this basis the division of the compounds into two groups can be seen, those containing hydrogen atoms and those not containing hydrogen atoms. Nitrogen was previously found [3] to lie intermediate between the two. The extinguishing concentrations of perfluorocarbons occur around 10\% (vol.) and the hydrofluorocarbons fall between $15 \%$ and $30 \%$ (vol.). At low concentrations nitrogen is better than the hydrofluorocarbons and some perfluorocarbons, but at high concentrations nitrogen is the worst [3].

Among the alternative agents the HFC-32/125 mixture displays the worst extinguishing characteristics. $\mathrm{C}_{4} \mathrm{~F}_{10}$ has the best performance from the Mach number point of view and $\mathrm{C}_{2} \mathrm{~F}_{6}$ is the best from the pressure ratio point of view at low concentrations. In comparison, halon 1301 is a bit less effective than $\mathrm{C}_{4} \mathrm{~F}_{10}$ and $\mathrm{C}_{2} \mathrm{~F}_{6}$ but more effective than the remainder of the alternatives. 


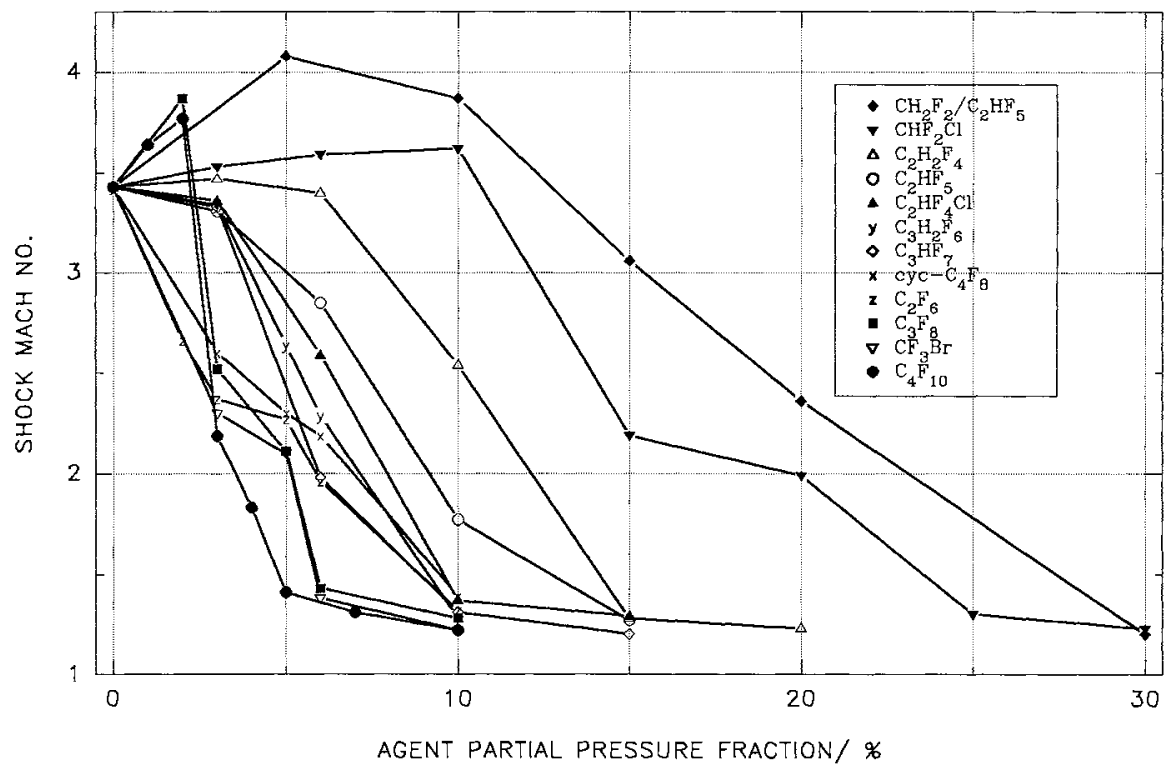

FIGURE 4. Suppression effectiveness of the agents in the $5 \%$ vol. $\mathrm{C}_{2} \mathrm{H}_{4} /$ Air mixture based on shock Mach No. versus agent partial pressure fraction. Initial temperature, $295 \mathrm{~K}$, and pressure, $100 \mathrm{kPa}$.

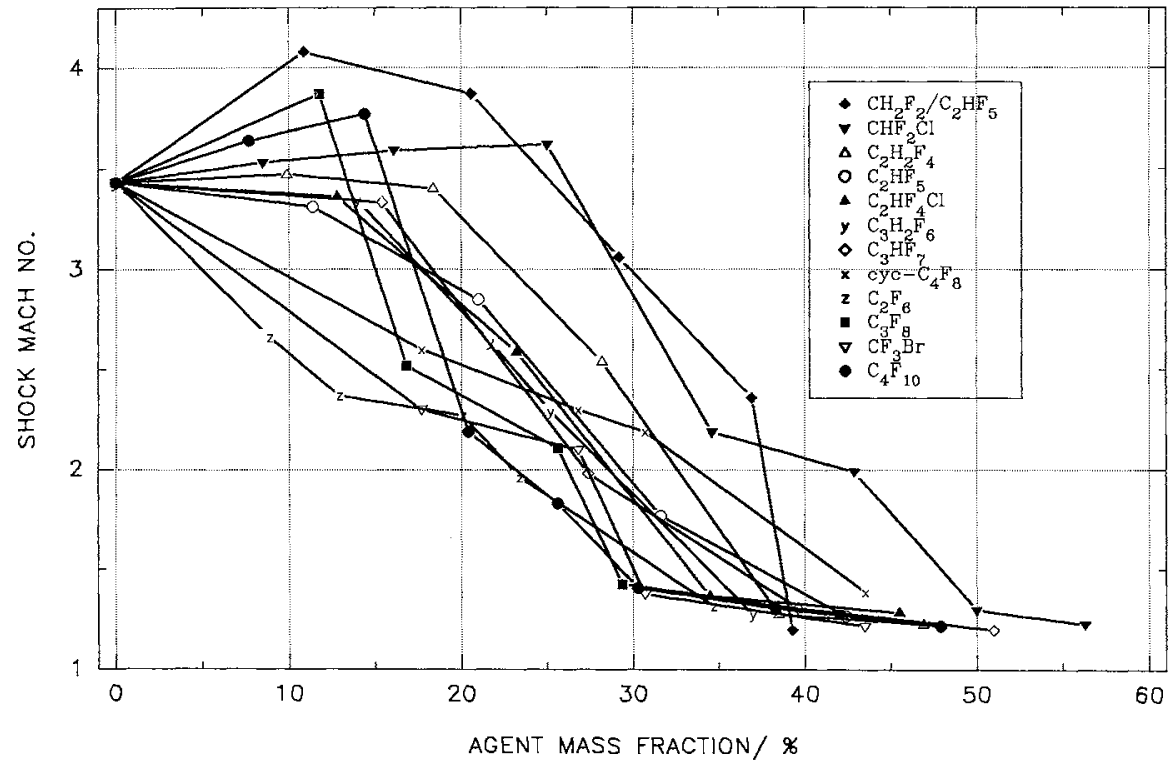

FIGURE 5. Suppression effectiveness of the agents in the $5 \%$ vol. $\mathrm{C}_{2} \mathrm{H}_{4} / \mathrm{Air}$ mixture based on shock Mach No. versus agent mass fraction. Initial temperature, $295 \mathrm{~K}$, and pressure, $100 \mathrm{kPa}$. 


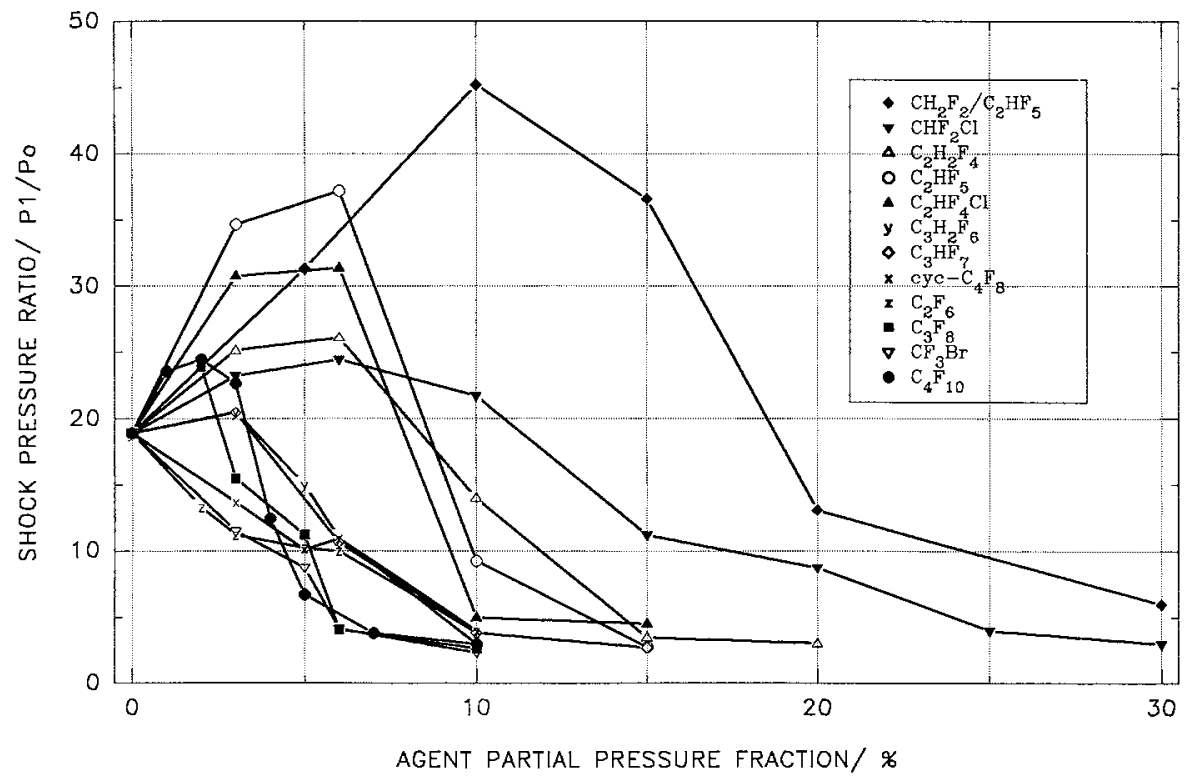

FIGURE 6. Suppression effectiveness of the agents in the $5 \%$ vol. $\mathrm{C}_{2} \mathrm{H}_{4} /$ Air mixture based on shock pressure ratio versus agent partial pressure fraction. Initial temperature, $295 \mathrm{~K}$, and pressure, $100 \mathrm{kPa}$.

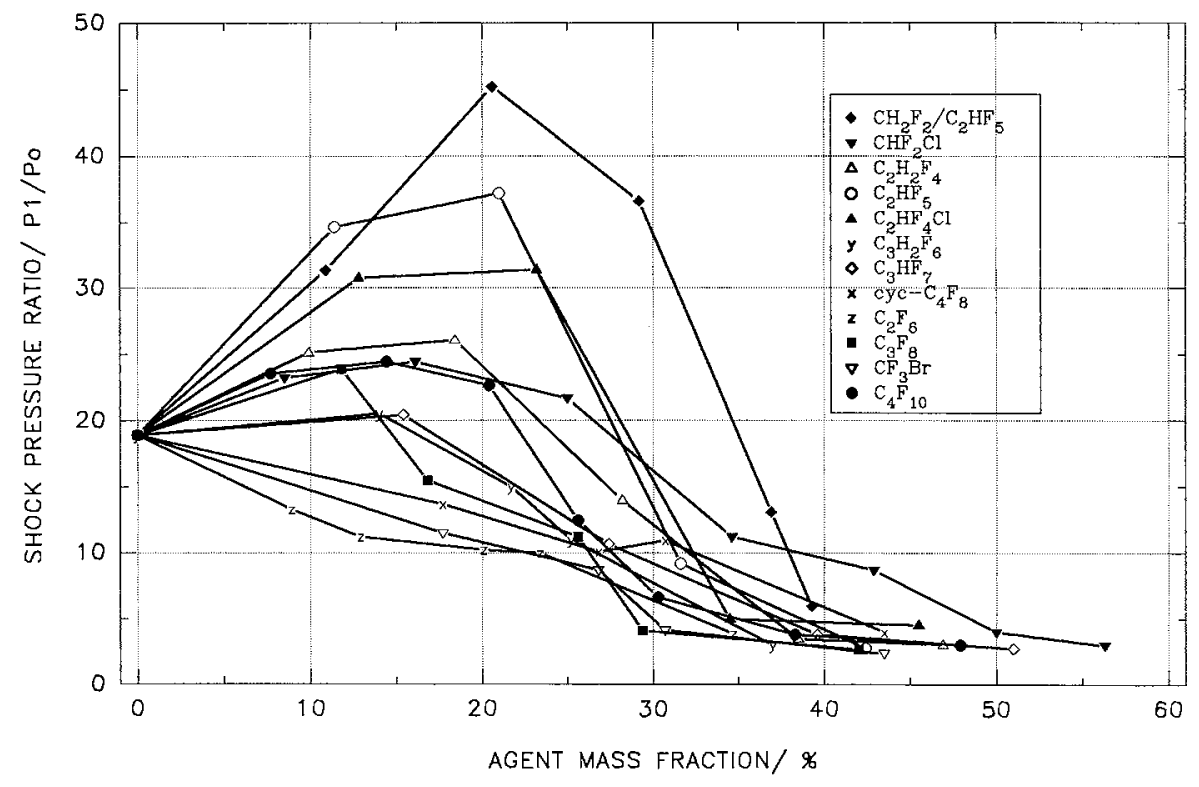

FIGURE 7. Suppression effectiveness of the agents in the $5 \%$ vol. $\mathrm{C}_{2} \mathrm{H}_{4} /$ Air mixture based on shock pressure ratio versus agent mass fraction. Initial temperature, $295 \mathrm{~K}$, and pressure, $100 \mathrm{kPa}$. 
The relative behavior of the various agents changes depending upon concentration, whether or not the evaluation criteria is Mach number or pressure ratio, and whether or not one is interested in minimizing agent volume or mass. For the present study, it is assumed that the primary performance criterion is the minimization of pressure build-up; that a $50 \%$ reduction in pressure ratio defines the agent concentration; that agent mass, dispersed volume and storage volume are all important; and that the performance of $\mathrm{CF}_{3} \mathrm{Br}$ can be used to normalize the results.

Figure 8 displays three different performance parameters calculated with these assumptions. The flame suppression number (FSN) is defined as the mass fraction (or partial pressure fraction) of an agent required for suppression divided by the required mass fraction (or partial pressure fraction) of halon 1301. The volume factor is defined as the storage volume of the alternative agent necessary for suppression divided by the storage volume of the halon 1301. The saturated liquid density of the agents at $20^{\circ} \mathrm{C}$ is used to convert mass to volume. Halon 1301 has a volume factor and an FSN of unity; the smaller these values, the better the agent.

While there are some reversals depending upon the basis of evaluation, Figure 8 shows that the perfluorocarbons are clearly the best performers and the HFC-32/125 mixture is the worst. HCFC-124 is the best of the non-perfluorocarbons. By comparison, the FSN(mass), FSN(partial pressure) and volume factor for nitrogen were found to be $1.2,6.8$, and 32 , respectively.

\section{CONCLUSIONS}

1) Suppression of highly dynamic flames can be effectively studied in the two-sectional deflagration/detonation tube, permitting clear discrimination of performance among various alternative extinguishing agents.

2) The fast flame under suppression strictly follows the shock wave, which is always ahead of it in such a way that its velocity is the same as the shock velocity. The distance between the flame and the shock increases with the amount of an extinguishing agent. At the extinguishment point the flame radiation disappears while the residual shock wave still exists.

3) The analysis of the suppression data for the lean ethene/air mixture leads to the division of the alternative compounds under consideration into two groups:

- perfluorocarbons, which are more effective,

- hydrofluorocarbons and hydrochlorofluorocarbons, which are less effective.

Within each group the agents can be ordered approximately according to the molecular weight and simultaneously according to the number of the halogen atoms in a molecule.

4) The extinguishing concentrations of the more effective agents are around $10 \%$ by volume and $40 \%$ by mass, while less effective ones are $15-30 \%$ by volume and $40-50 \%$ by mass. The most effective agents are $\mathrm{C}_{4} \mathrm{~F}_{10}, \mathrm{C}_{3} \mathrm{~F}_{8}$ and $\mathrm{C}_{2} \mathrm{~F}_{6}$. The least effective is the 


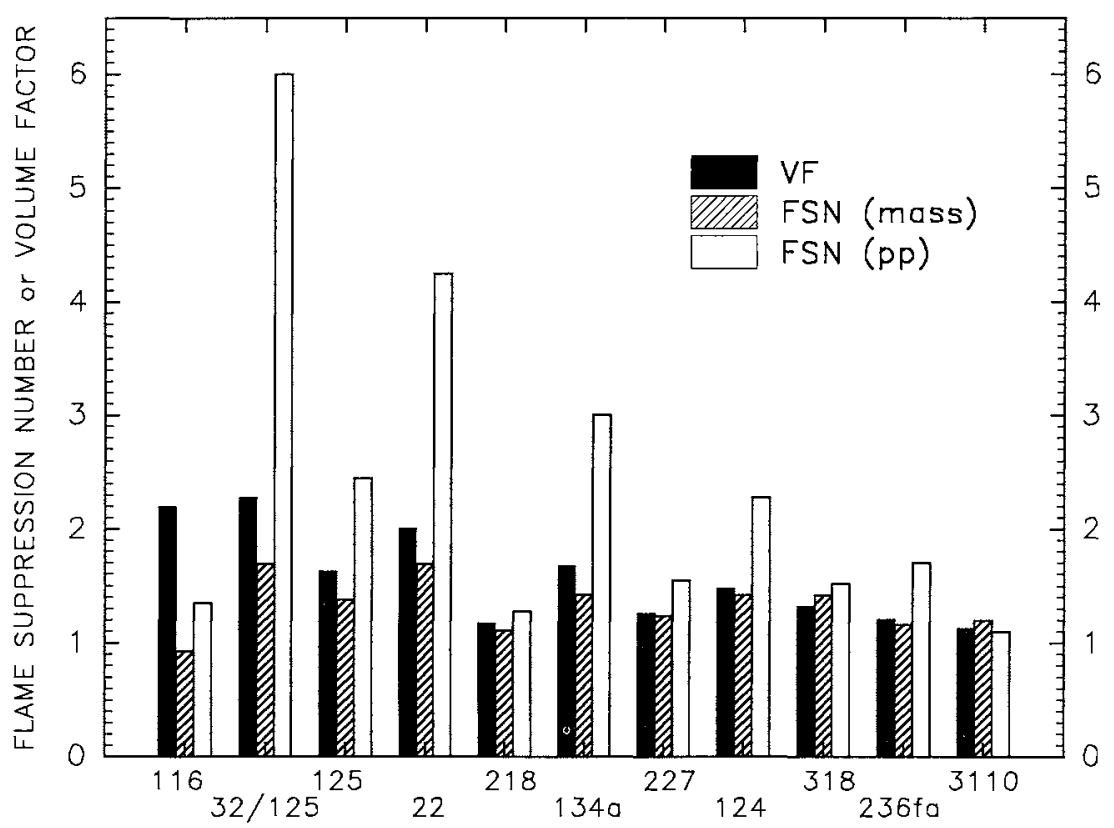

FIGURE 8. Volume factor and flame suppression numbers (based upon mass and partial pressure) versus alternative agents. The agents are ordered according to increasing boiling point.

$\mathrm{CH}_{2} \mathrm{~F}_{2} / \mathrm{C}_{2} \mathrm{HF}_{5}$ mixture, giving unusually high pressure ratios. $\mathrm{CHF}_{2} \mathrm{Cl}$ requires the highest concentration of all the alternative agents to extinguish the flame radiation.

5) The presence of a hydrogen-containing suppressant in the lean ethene/air mixture results in a significant increase in pressure ratio relative to that for the pure combustible mixture. The phenomenon occurs also for the compounds not containing hydrogen atoms (except for $\mathrm{C}_{2} \mathrm{~F}_{6}$ ) at relatively lower concentrations but the impact is not so dramatic. It is suggested that for the hydrofluoro- and hydrochlorofluorocarbons the effect is both thermodynamic and kinetic while for the fluorocarbons it is purely thermodynamic.

\section{ACKNOWLEDGEMENT}

The authors wish to acknowledge the U.S. Air Force, Navy, Army and Federal Aviation Administration for funding the Agent Screening for Halon 1301 Aviation Replacement project. The program is under the direction of Mr. Michael Bennett at the Wright Patterson AFB Flight Dynamics Laboratory, Vehicle Subsystems Division, Survivability Enhancement Branch. 


\section{REFERENCES}

1. Grosshandler, W.L., Gann, R.G., and Pitts, W.M., editors, "Evaluation of Alternative In-flight Fire Suppressants for Full- scale Testing in Simulated Aircraft Engine Nacelles and Dry Bays," NIST Special Publication 861, April 1994.

2. Grosshandler, W., Lowe, D., Rinkinen, W. and Presser, C., "A Turbulent Spray Burner for Assessing Halon Alternative Fire Suppressants," Symposium on Fire and Combustion, ASME Winter Annual Meeting, December 1993.

3. Gmurczyk, G., Grosshandler, W., Peltz, M. and Lowe, D., "A Facility for Assessing Suppression Effectiveness in High Speed Turbulent Flames," Eastern States Section Conference/The Combustion Institute, Princeton, October 1993.

4. Baker, W.E., Cox, P.A., Westine, P.S., Kulesz, J.J., and Strehlow, R.A., Explosion Hazards and Evaluation, Elsevier, 1983.

5. Lee, J.H.S., "Fast Flames and Detonations," Chemistry of Combustion Processes, The American Chemical Society, 1984.

6. Nettleton, M.A., Gaseous Detonations: Their Nature, Effects and Control, Chapman and Hall, 1987.

7. Chapman, W.R., and Wheeler, R.N.V., "The Propagations of Flame in Mixtures of Methane and Air. Part IV. The Effect of Restrictions in the Path of the Flame," Journal of the Chemical Society, 2139-2147, London, Part II - 1926.

8. Lee, J.H., Knystautas, R. and Chan, C.K., "Turbulent Flame Propagation in Obstacle-filled Tubes," Twentieth Symposium (International) on Combustion, pp. 1663-1672, The Combustion Institute, 1984.

9. Peraldi, O., Knystautas, R. and Lee, J.H., "Criteria for Transition to Detonation in Tubes," Twenty-first Symposium (International) on Combustion, pp. 1629-1637, The Combustion Institute, 1986.

10. Heinonen, E.W., Kirst, J.A. and Moussa, N.A., "Fire/Explosion Protection Characterization and Optimization: Alternative Dry Bay Fire Suppression Agent Screening, Medium-Scale Test Results," Final Report, NMERI OC 91/16, Report JTCG/AS-91-VR-005, 1991.

11. Das, A., "Relationship Between Ignition Source Strength and Design Inerting Concentration of Halon 1301," M.S. Thesis, Fire Protection Engineering Department, Worcester Polytechnic Institute, 1986.

12. Sheinson, R.S., Penner-Hahn, J.E., and Indritz, D., "The Physical and Chemical Action of Fire Suppressants," Fire Safety Journal 15, 437-459, 1989. 